\title{
Point of Care Ultrasound in Geriatric Patients at the Emergency Department
}

\author{
Kamonwon lenghong ${ }^{1}$, Somsak Tiamkao ${ }^{2}$, Vajarabhongsa Bhudhisawasdi ${ }^{1}$, Dhanu Gaysonsiri ${ }^{3}$, Korakot Apiratwarakul $^{1 *}$ \\ ${ }^{1}$ Department of Emergency Medicine, Faculty of Medicine, Khon Kaen University, Khon Kaen, Thailand; ${ }^{2}$ Department of \\ Medicine, Faculty of Medicine, Khon Kaen University, Khon Kaen, Thailand; ${ }^{3}$ Department of Pharmacology, Faculty of Medicine, \\ Khon Kaen University, Khon Kaen, Thailand
}

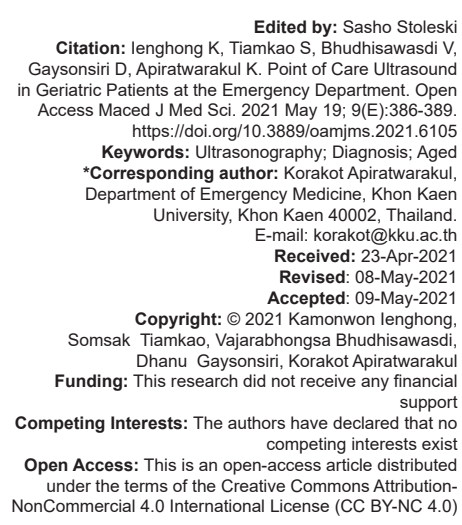

Edited by: Sasho Stolesk Citation: lenghong K, Tiamkao S, Bhudhisawasdi V Gaysonsiri D, Apiratwarakul K. Point of Care Ultrasound in Geriatric Patients at the Emergency Department. Open (E) https://doi.org/10.3889/oamjms.2021.610
Keywords: Ultrasonography; Diagnosis; Aged *Corresponding author: Korakot Apiratwaraku, Department of Emergency Medicine, Khon Kaen University, Khon Kaen 40002, Thailand. E-mail: korakot@kku.ac.th Received: 23-Apr-202 Revised: 08-May-202 Accepted: 09-May-202 Copyright: ๑ 2021 Kamonwon lenghong Somsak Tiamkao, Vajarabhongsa Bhudhisawasdi, Funding: This research did not receive any financial Competing Interests: The authors have declared that no competing interests exis
Open Access: This is an open-access article distribute
under the terms of the Creative Commons AttributionNonCommercial 4.0 International License (CC BY-NC 4.0)

\section{Abstract}

BACKGROUND: Point of care ultrasound (POCUS) plays an important role as a crucial tool for the diagnosis of various conditions in emergency and critical ill patients. However, POCUS examination in elderly populations has not been well studied.

AIM: This was a retrospective observational study of elderly patients at the Department of Emergency Medicine who had received POCUS examination at a tertiary university hospital, Thailand.

METHODS: The study was conducted throughout January 2020-December 2020. Patients' characteristics and ultrasonography findings were recorded.

RESULTS: A total of 191 elderly patients were evaluated. Median patient age was 75.65 years; $56.02 \%$ of patients were female. Chief complaints where POCUS scans were applied were respiratory $(36.65 \%)$ and cardiovascular system-related $(21.99 \%)$. The most frequent procedures performed were cardiac, lung, and inferior vena cava examinations. Abnormal ultrasound findings were discovered in 133 patients $(68.91 \%)$. The $66.17 \%$ of abnormal ultrasound findings were associated with final diagnosis. The admission rate of elderly patients $(56.82 \%)$ was highest among patients with positive ultrasound findings associated with final diagnosis.

CONCLUSIONS: POCUS utilization in elderly patients was useful in aiding emergency physicians amid diagnosis of various diseases, especially life-threatening ones.

\section{Introduction}

Nowadays, more than half of 75-year-olds have had at least one visit to an emergency department [1] in the United States. Statistics showed that elderly patients made up $10-20 \%$ of the emergency population [2], [3]. In Thailand, $6.6 \%$ of overall patients who attended the ED were aged more than 65 years [4]. As demographics have changed, people are living longer. Hence, the number of elderly persons has increased [5]. The healthcare system should be prepared to take care of these people as the medical care required is of greater sophistication. A survey revealed that over $45 \%$ of emergency physicians have been faced with greater difficulty in the management of elderly patients compared with younger patients [6].

Point of care ultrasound (POCUS) is essential in the care of patients at the emergency department [7]. It can be used to improve diagnosis, perform procedures, rapidly assess patients in the emergency department, and improve patient outcomes [8], [9], [10], [11]. POCUS is being applied more widely in emergency patients and critically ill patients - including the elderly population [12].
Previous ultrasound studies have examined selected groups of elderly patients such as those exhibiting life-threatening conditions such as aortic dissection [13], acute myocardial infarction [14], and abdominal aorta aneurysm [15]. Ultrasound findings in elderly patients in undifferentiated medical conditions in the Emergency Department have never been documented. Hence, the present study aimed to determine POCUS findings in the geriatric population who came to visit the Accident and Emergency Department of Srinagarind Hospital, Faculty of Medicine, Khon Kaen University.

\section{Methods}

\section{Study design}

This was a retrospective, single-centered, and observational study at a tertiary university hospital in Thailand. Ethical approval was provided by the Khon Kaen University Ethics Committee for Human Research and registered with the Thai Clinical Trials Registry (HE641197). 


\section{Sample size}

We included patients aged $\geq 65$ years who had received POCUS and had ultrasound video clips and images recorded by the ultrasound machine at the emergency department throughout January 2020-December 2020. Patients with no ultrasound documents were excluded from the study. The sample size for the analysis of the estimated sample size was determined. Prevalence was 0.854 [16]. Standard normal value was 1.96. Power analysis was determined using an alpha of 0.05 and absolute precision was 0.05 . This resulted in an estimated desired effect sample size of at least 191 subjects.

\section{Study protocol}

The study was performed throughout January 2020-December 2020. We collected data from patients aged $\geq 65$ years who visited the emergency department and completed POCUS examination with convenience sampling. Ultrasound was performed by emergency medicine residents and the attending physician. Data collected for the present study included ultrasound findings from video clips and images recorded using the ultrasound machine at the emergency department, as well as patients' characteristics, final diagnosis, and patients' disposition. This study was conducted with a standard ultrasound machine (Mindray M9) which we used at the emergency department. All ultrasound video clips and images were reviewed by the emergency ultrasound expert. If ultrasound findings and final diagnosis were the same, the ultrasound finding was considered as associated with the final diagnosis. The primary outcome of this study aimed to determine the ultrasound findings of elderly patients who visited the emergency department.

\section{Statistical analysis}

The authors employed means and standard deviations to describe continuous variables. Counts and percentages were applied for categorical variables. All statistical analyses were performed using the software Stata version 10.1 (Stata Corp, College Drive, TX, USA). Statistical significance was defined as a twosided $p$-value of 0.05 or less.

\section{Results}

From January to December 2020, this study included 191 patients (Table 1). Median age was $75.65 \pm 7.68$ years and $56.02 \%$ were female. All patients in this study were non-trauma patients. Most patients exhibited triage at level $2(36.6 \%)$ and $3(39.79 \%)$ according to the emergency severity index triage system index (ESI). The most common chief complaint was associated with the respiratory system $(36.65 \%)$. Most patients had the ultrasound performed at their
Table 1: Patients' characteristics

\begin{tabular}{ll}
\hline Patient characteristics $(\mathrm{n}=191)$ & Number \\
\hline Sex & \\
Female, $\mathrm{n}(\%)$ & $107(56.02)$ \\
Age & \\
$\quad$ Mean \pm SD & $75.65 \pm 7.68$ \\
Patient type & \\
$\quad$ Non-trauma, $\mathrm{n}(\%)$ & $191(100)$ \\
Triage level, $\mathrm{n}(\%)$ & \\
ESI level 1 & $5(2.61)$ \\
ESI level 2 & $70(36.6)$ \\
ESI level 3 & $76(39.79)$ \\
ESI level 4 & $40(20.94)$ \\
ESI level 5 & 0 \\
Chief complaint, $\mathrm{n}$ (\%) & \\
Respiratory system & $70(36.65)$ \\
Cardiovascular system & $42(21.99)$ \\
Immunology system & $37(19.37)$ \\
Gastrointestinal system & $25(13.09)$ \\
Neurology system & $11(5.76)$ \\
Hepatobiliary system & $3(1.57)$ \\
Kidney and urinary bladder system & $2(1.05)$ \\
Bone and musculoskeletal system & $1(0.52)$ \\
Area of ultrasound examination, $\mathrm{n}(\%)$ & \\
Cardiac & $151(79.06)$ \\
Lung & $78(40.84)$ \\
Inferior vena cava & $53(27.75)$ \\
Abdomen (liver, gall bladder) & $21(10.99)$ \\
Abdominal aorta & $7(3.67)$ \\
Kidney and urinary bladder & $5(2.62)$ \\
Femoral vein & $5(2.62)$ \\
Skin and soft tissue & $4(2.09)$ \\
Abnormal findings amid Pocus examination, $\mathrm{n}(\%)$ & $133(68.91)$ \\
\hline POCUS: Point of care ultrasound. & \\
& \\
\hline
\end{tabular}

cardiac region (78.53\%) followed by the lung region (40.3\%). Accordingly, most patients received ultrasound in more than one area. Most ultrasound examinations combined cardiac, lung, and inferior vena cava imaging. This study revealed abnormal ultrasound findings in 133 patients (68.91\%).

This study revealed 88 patients with abnormal ultrasound findings which were associated with the final diagnosis $(66.17 \%)$ (Table 2$)$.

Table 2: Ultrasound findings associated with final diagnosis categorized by disease $(n=88)$

\begin{tabular}{ll}
\hline Final diagnosis & Abnormal ultrasound findings, $\mathrm{n}(\%)$ \\
\hline Pneumonia & $24(27.27)$ \\
Heart failure & $18(20.45)$ \\
Myocardial infarction & $14(15.91)$ \\
Hypovolemia & $10(11.36)$ \\
Acute cholangitis & $4(4.55)$ \\
Urinary tract infection with obstructive uropathy & $4(4.55)$ \\
Cardiac arrest & $4(4.55)$ \\
Gall stone & $2(2.27)$ \\
Cellulitis & $2(2.27)$ \\
Pericardial effusion & $1(1.14)$ \\
Liver mass & $1(1.14)$ \\
Renal abscess & $1(1.14)$ \\
Necrotizing fasciitis & $1(1.14)$ \\
Abdominal aortic aneurysm & $1(1.14)$ \\
Aortic dissection & $1(1.14)$ \\
\hline
\end{tabular}

Besides that, the disposition of patients presenting abnormal ultrasound findings associated with the final diagnosis was shown as admitted to hospital $(50 / 88,56.82 \%)$, discharged from the emergency room $(18 / 88,20.45 \%)$, referred to another hospital (14/88, $15.91 \%)$, and death $(4 / 88,4.55 \%)$.

\section{Discussion}

The present study described 191 elderly patients who underwent POCUS examination at the 
emergency department. Moreover, the present study was comprised predominantly of females which was comparable to prior studies [2], [4]. All patients in this study were non-trauma patients, which was a contrast to other studies [2], [3] that indicated $20-30 \%$ of elderly patients as trauma patients. The most common injury type was falls. However, this may be explained by the fact that most patients in our ER were nontrauma patients (80\%). Overall, $79 \%$ patients who had undergone POCUS were triaged as urgent, emergency, and critical level, which was consistent with a study by Latham et al. [2]. In the author's opinion, most elderly patients had a lot of comorbid diseases which were of greater severity than in other age groups [17]; thus, these patients were triaged as a higher level and required greater complexity of investigation such as POCUS examination. The most common chief complaint in this study was categorized as respiratory system related, which was consistent with other studies [2], [4], [18]. A study by Fröhlich et al. demonstrated that the main indication for the ultrasound examinations was dyspnea $(44.6 \%)$. Our study revealed that most ultrasound areas of examination were in the cardiac and lung regions, which was congruent with a prior study [12]. Nevertheless, that study reported the area of ultrasound examination in critically ill patients, that is, a different population.

Our study revealed abnormal ultrasound findings at the rate of $68.91 \%$. Moreover, patients with abnormal ultrasound findings accounted for $66.17 \%$ which was associated with the final diagnosis. Nevertheless, our study stated a lower rate than a previous study which reported that $85.42 \%$ of scans provided useful information in confirming or refuting a suspected diagnosis [16]. The present study detected various life-threatening conditions in elderly patients which was similar to a previous study [19], including pneumonia (27.27\%), heart failure (20.45\%), and myocardial infarction (15.91\%) [20]. Furthermore, the POCUS examination detected vascular emergency conditions, including abdominal aortic aneurysm and aortic dissection [21] despite there being a small number of subjects in this study. In terms of musculoskeletal and obstetrics and gynecology examination, our emergency physicians were not familiar with these examinations due to our ultrasound curriculum. Thus, there were no POCUS examinations of these types in this study. However, POCUS examination to diagnose musculoskeletal-related injuries was reported as a potentially useful tool in elderly patients [22].

The strengths of this study were: (1) The study findings demonstrated the impact of applying POCUS in the elderly population at the Emergency Department. Our study revealed greater than $60 \%$ of POCUS findings which were useful to produce evidence of final diagnosis. Limitations of the study were first, due to the nature of the retrospective study, some data were missing or incomplete [23], [24], [25], [26].
Second, the setting of the present study was in a tertiary university hospital, which may exhibit different patterns of patients to primary or secondary care hospitals. The last limitation was, we reported solely on the relationship between POCUS findings and final diagnosis/dispositions, thus, the results of this study cannot be evaluated for diagnostic accuracy amid POCUS examination.

\section{Conclusion}

POCUS utilization in elderly patients was applicable. POCUS allows for sufficient information to aid the clinical diagnosis of emergency physicians. In addition, POCUS can be employed to identify lifethreatening conditions. Further research is warranted to clarify diagnostic accuracy in certain diseases in the elderly population.

\section{Acknowledgments}

The authors would like to thank all participants in this study as well as Mr. Ross Lacey, for acting as an English consultant.

\section{References}

1. Hwang $U$, Morrison RS. The geriatric emergency department. J Am Geriatr Soc. 2007;55(11):1873-6. http://doi. org/10.1111/j.1532-5415.2007.01400.x

PMid: 17916122

2. Latham LP, Ackroyd-Stolarz S. Emergency department utilization by older adults: a descriptive study. Can Geriatr J. 2014;17(4):118-25. http://doi.org/10.5770/cgj.17.108 PMid:25452824

3. Ezaki T, Yamada T, Yasuda M, Setoguchi H, Noda E, Kanna T, et al. Geriatric patients presenting to the emergency department of a Japanese university hospital. Fukuoka Igaku Zasshi. 2006;97(9):269-76

PMid:17134030

4. Maneekun W, Thatphet P, Kotruchin P, Tantibundit P. Tha geriatric emergency patients' registry in tertiary care hospitals. $J$ Med Assoc Thai. 2020;103:78-83.

5. United Nations: World population prospects: The 2008 revision, volume 1: Comprehensive tables and United Nations, world population prospects: The 2008 revision, highlights. Popul Dev Rev. 2010;36:854-5.

6. McNamara RM, Rousseau E, Sanders AB. Geriatric emergency medicine: A survey of practicing emergency physicians. Ann Emerg Med. 1992;21(7):796-801. http://doi.org/10.1016/ s0196-0644(05)81024-8 


\section{PMid:1610035}

7. Stein JC, River G, Kalika I, Hebig A, Price D, Jacoby VL, et al. A survey of bedside ultrasound use by emergency physicians in California. J Ultrasound Med. 2009;28(6):757-63. http://doi. org/10.7863/jum.2009.28.6.757

PMid:19470816

8. Moore CL, Gregg S, Lambert M. Performance, training, quality assurance, and reimbursement of emergency physicianperformed ultrasonography at academic medical centers. J Ultrasound Med. 2004;23(4):459-66. http://doi.org/10.7863/ jum.2004.23.4.459

PMid:15098862

9. Mandavia DP, Hoffner RJ, Mahaney K, Henderson SO. Bedside echocardiography by emergency physicians. Ann Emerg Med. 2001;38(4):377-82. http://doi.org/10.1067/mem.2001.118224 PMid: 11574793

10. Singer AJ, Williams J, Taylor M, Le Blanc D, Thode HC Jr. Comprehensive bedside point of care testing in critical ED patients: A before and after study. Am J Emerg Med. 2015;33(6):776-80. http://doi.org/10.1016/j.ajem.2015.03.034 PMid:25836947

11. Adhikari S, Stolz L, Amini R, Blaivas M. Impact of point-of-care ultrasound on quality of care in clinical practice. Rep Med Imag. 2014;81:81-93. https://doi.org/10.2147/RMI.S40095

12. lenghong K, Towsakul N, Bhudhisawasdi V, Srimookda N, Ratanachotmanee N, Phungoen P. POCUS findings in critically III patients in emergency department. J Med Assoc Thai. 2021;104:54-8. https://doi.org/10.35755/jmedassocthai.2021. S01.12228

13. Fojtik JP, Costantino TG, Dean AJ. The diagnosis of aortic dissection by emergency medicine ultrasound. J Emerg Med. 2007;32(2):191-6. http://doi.org/10.1016/j. jemermed.2006.07.020 PMid:17307632

14. Nicolosi GL, Golcea S, Ceconi C, Parrinello G, Decarli A, Chiariello $\mathrm{M}$, et al. Effects of perindopril on cardiac remodelling and prognostic value of pre-discharge quantitative echocardiographic parameters in elderly patients after acute myocardial infarction: The PREAMI echo sub-study. Eur Heart J. 2009;30(13):1656-65. http://doi.org/10.1093/eurheartj/ehp139 PMid:19406871

15. lecovich E, Carmel S. Differences in accessibility, affordability, and availability (AAA) of medical specialists among three age-groups of elderly people in Israel. J Aging Health. 2009;21(5):776-97. http://doi.org/10.1177/0898264309333322 PMid:19282268

16. Coles JA, Beynon GP, Lees WR. The use of ultrasound in geriatric medicine. Age Ageing. 1982;11(3):145-52. http://doi. org/10.1093/ageing/11.3.145

PMid:7124553

17. Lau GK. Elderly patients in the accident and emergency department. Hong Kong Med J. 1987;39:168-72.

18. Fröhlich E, Beller K, Muller R, Herrmann M, Debove I, Klinger $\mathrm{C}$, et al. Point of care ultrasound in geriatric patients: Prospective evaluation of a portable handheld ultrasound device. Ultraschall Med. 2020;41(3):308-16. http://doi. org/10.1055/a-0889-8070

PMid:31026863

19. Eurle B, Butler K. Diagnostic ultrasonography in emergency medicine. Crit Decis Emerg Med. 2004;18:1-8.

20. Camerieri A, Picano E, Landi P, Michelassi C, Pingitore A, Minardi G, et al. Prognostic value of dipyridamole echocardiography early after myocardial infarction in elderly patients. Echo Persantine Italian Cooperative (EPIC) study group. J Am Coll Cardiol. 1993;22(7):1809-15. http://doi. org/10.1016/0735-1097(93)90762-p

PMid:8245333

21. Barrett C, Stone MB. Emergency ultrasound diagnosis of Type A aortic dissection and apical pleural cap. Acad Emerg Med. 2010;17(4):e23-4. http://doi. org/10.1111/j.1553-2712.2010.00709.x PMid:20345426

22. Bücklein W. Sonographische notfalldiagnostik am bewegungsapparat. [Emergency ultrasound diagnosis of the musculoskeletal system]. Rontgenpraxis. 1999;52(3-4):103-9. PMid: 10522450

23. Apiratwarakul $K$, lenghong $K$, Gaysonsiri $D$, Mitsungnern $T$, Buranasakda M, Bhudhisawasdi V. The effectiveness of oxygen-powered inhalation devices in prehospital care. J Med Assoc Thai. 2020;103(Suppl 6):58-60.

24. lenghong $\mathrm{K}$, Kotruchin $\mathrm{P}$, Tangpaisarn $\mathrm{T}$, Apiratwarakul $\mathrm{K}$. Practical emergency ultrasound flashcards with augmented reality in teaching point-of-care ultrasound in ER. Open Access Maced J Med Sci. 2021;9(E):39-42. https://doi.org/10.3889/ oamjms.2021.5566

25. lenghong $\mathrm{K}$, Kleebbuakwan $\mathrm{K}$, Apiratwarakul $\mathrm{K}$, Phungoen $\mathrm{P}$, Gaysonsiri D, Bhudhisawasdi V. Comparison of cleaning methods for ultrasound probes at an emergency department in a resource-limited country. J Med Assoc Thai. 2020;103(Suppl 6):67-71

26. Apiratwarakul $K$, Songserm $W$, lenghong $K$, Phungoen $P$, Gaysonsiri D, Bhudhisawasdi V. The role of mechanical cardiopulmonary resuscitation devices in emergency medical services. J Med Assoc Thai. 2020;103(Suppl 6):98-101. 